\title{
Special Issue with Selected Papers from the 10th International Conference Virtual University Bratislava
}

\author{
$\underline{\text { doi:10.3991/ijet.v6iS1.1625 }}$
}

The 6 papers in this special issue represent a selected sample of more than 40 papers presented at the jubilee 10th International Conference Virtual University held in Bratislava in December 2009.

Electronic learning environments are now increasingly used by all universities - by the ones based entirely on the distance teaching approaches dominated by modern information and communication technologies (ICT), by those trying to optimize the learning environment by blending all possible learning paradigms, as well as by those that are still dominantly profiting from the traditional class-based education, whereby they integrate the new ICTs as an additional bonus.

Although the papers presented at the conference (available on line at the web page http://virtuni.eas.sk/rocnik/2009/?main=program) focus on all aspects of development of a virtual university environment - from simple course delivery, through the level that enables rich and motivating interactions among students, teachers and the course content, or the e-labs hosting the course assignment and exercises that should enable effective acquiring of "authentic" working skills in an "authentic" working environment, up to the top university level that should ensure synergy of all university subsystems and individual actors oriented towards efficient university functioning - all selected papers concentrate on such more advanced aspects of elearning. Two of these papers were successfully submitted to the e-learning competition held traditionally as integral part of the conference.

In the first decade of its existence the conference Virtual University has helped many teachers and e-learning experts in their personal development - many of the original "beginners" grew far above their original teachers. We hope that the conference will successfully continue also into the 2 nd decade of its existence and still attract enthusiastic contributions inspiring many new fans of e-learning, it does not matter from which e-learning sector or position they come. We are looking forward to meet you at the 11th Virtual University in September 2011.

\section{Editors:}

Mikuláš Huba received the MSc. and PhD. Degrees in Technical Cybernetics from Slovak University of Technology in Bratislava in 1974 and 1982, respectively. Since 1989 he was a Senior Lecturer and Head of the Control Theory Group of the Institute of Control and Industrial Informatics and from 2008 Full Professor at the Faculty of Electrical Engineering and Information Technology. In 1996 he initiated the establishment of the university Distance Education Centre and worked as its director up to 2008. Since 2008 he was also active in research at the Fern Universität Hagen, Germany, where he now continues as the Mercator visiting professor. He is author and co-author of more than 200 papers in journals and proceedings of international conferences and 20 monographs on Constrained, Nonlinear and Remote Control and about e-Learning.

Celina Pinto Leão received her MSc degree in Industrial Mathematics from University of Strathclyde/Glasgow Caledonian University, Scotland, in 1994, and in 2003 her PhD in Engineering Science from Porto University, Portugal. Presently she is at University of Minho, Portugal, as an assistant professor and as a researcher with the Algoritmi Center. Her main interests are in modeling and simulation of processes, and in the application of new methodologies in the learning process of numerical methods and statistics in engineering. Principal investigator and member of funding projects, being the results published in international journals, conference proceedings and chapters in books.

Maria Teresa Restivo received a Physics degree and a Ph.D. in Engineering Science both at the University of Porto (UP). She became Assistant researcher in 1988 and she is Senior Researcher since 1995 in UP Faculty of Engineering. She works in the automation, instrumentation and control area and also teaches at under and post-graduate levels. She is the Coordinator of the System Integration and Process Automation Research Unit at Institute of Mechanical Engineering (IDMEC-Polo FEUP). Her R\&D interests are in metrology, sensors and transducers development and their integration with wireless systems, virtual instrumentation and new technologies for web remote control. She also is interested in exploring the use of ITs, of R\&V labs and haptic interaction with VR in engineering education and training activities. She is author of more than 100 papers in journals, conference proceedings, books or book chapters. She holds three patents and two other pending. She has been leader or team member of projects at national or international level. She is Executive Committee Member of International Society for Engineering Education - IGIP, President of Portuguese Society for Engineering Education - SPEE and Vice-President of IEEE Education Society Portuguese Chapter. 


\section{GUEST EDITORIAL}

Katarína Žáková is associate professor of cybernetics at Institute of Control and Industrial Technology, Faculty of Electrical Engineering and Information Technology, Slovak University of Technology with special interest in Internet based applications, virtual and remote laboratories and computer aided and online education. She has participated in several national and international projects and she is author or co-author more than 90 papers in journals, conference proceedings, textbooks or chapters in books.

Contact information

Mikuláš Huba,

Slovak University of Technology in Bratislava,

Fac. Electrical Engineering and Information technology,

Ilkovičova 3,812 19 Bratislava,

Slovakia,

tel. +421 260291 771, fax. +421265429 521,

email: mikulas.huba@stuba.sk

FernUniversität in Hagen, MI/PRT,

Philipp-Reis-Gebaeude, Universitaetsstr. 27,

D-58084 Hagen, Germany

Tel. +49 2331987 1105; Fax + 492331987354

mikulas.huba@fernuni-hagen.de 